
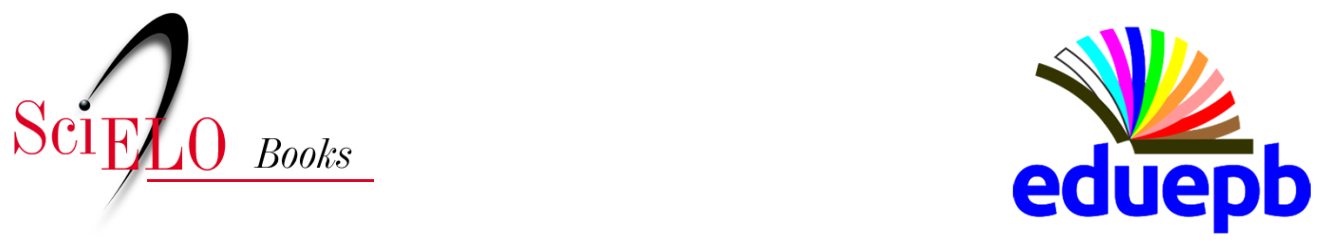

Parte II - Pensamentos e Contribuições

\title{
Capítulo VIII - Principais contribuições de Celso Furtado sobre a História Econômica do Brasil e o período recente
}

\author{
Wilson Cano
}

\section{SciELO Books / SciELO Livros / SciELO Libros}

CANO, W. Principais contribuições de Celso Furtado sobre a História

Econômica do Brasil e o período recente. In: SOUSA, C. M., THEIS, I. M., and BARBOSA, J. L. A., eds. Celso Furtado: a esperança militante (Interpretações): vol. 1 [online]. Campina Grande: EDUEPB, 2020, pp. 151-167. Projeto editorial 100 anos de Celso Furtado collection. ISBN: 978-65-86221-08-4. https://doi.org/10.7476/9786586221695.0010.

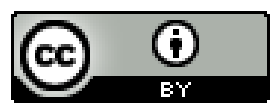

All the contents of this work, except where otherwise noted, is licensed under a Creative Commons Attribution 4.0 International license.

Todo o conteúdo deste trabalho, exceto quando houver ressalva, é publicado sob a licença Creative Commons Atribição 4.0.

Todo el contenido de esta obra, excepto donde se indique lo contrario, está bajo licencia de la licencia Creative Commons Reconocimento 4.0. 


\title{
Capítulo VIII
}

\section{Principais contribuições de Celso}

\author{
Furtado sobre a História Econômica
}

\author{
do Brasil e o período recente ${ }^{1}$
}

Wilson Cano

\begin{abstract}
$\mathrm{N}^{2}$ a monumental obra de Celso Furtado, o uso do método histórico-estrutural, tanto em suas obras mais analíticas quanto nas mais teóricas, está sempre presente, com o que se pode entender porque seus trabalhos, além da dimensão econômica, também sempre contemplaram os planos político e social.

Embora formado em direito, desde cedo se dedicou ao estudo da administração e planejamento públicos, ${ }^{3}$ e, posteriormente, à economia,
\end{abstract}

1 Texto apresentado no Seminário A atualidade do pensamento de Celso Furtado (1920-2004), patrocinado pelo Instituto de Geociências da Unicamp: Campinas, 26/11/2014. Constitui versão modificada e ampliada de Alguns temas relevantes sobre América Latina e Brasil tratados por Celso Furtado, publicado in Saboia e Carvalho. Republicado nesta Coletânea com autorização do autor, encaminhada aos organizadores pouco dias antes de sua morte, ocorrida em 03/05/2020.

2 Doutor em Ciências Econômicas pela Universidade Estadual de Campinas (1975). Foi professor titular da Unicamp, membro vitalício do conselho curador da Fundação Economia de Campinas e consultor da Fundação de Amparo à Pesquisa do Estado de São Paulo. Investigava, orientava, publicava e tinha experiência na área de Economia, com ênfase em Desenvolvimento Econômico, Economia Brasileira, Economia Latinoamericana e Economia Regional.

3 Notadamente entre 1946-1948, quando era técnico de administração do famoso Dasp — que foi uma verdadeira Universidade do Setor Público Brasileiro —, onde conviveu com expressivos personagens que prestaram importantes serviços à reestruturação do Estado Nacional e no trato dos problemas da economia brasileira. 
principalmente em seu doutoramento em Paris, em 1948, com a tese $A$ economia colonial brasileira nos séculos XVI e XVII, a partir da qual escreveria, em 1957-1958, sua obra prima - Formação econômica do Brasil. Suas reflexões teóricas sobre o subdesenvolvimento tiveram como base principal os trabalhos iniciais na Cepal, a partir de 1949, de cuja equipe principal fez parte, sob a direção de Raúl Prebisch, cujos trabalhos ali iniciados constituíram a base sobre a qual frutificaram importantes desdobramentos realizados de forma coletiva ou individual. ${ }^{4}$

O esforço realizado por Furtado - notadamente o de situar historicamente suas análises de países latino-americanos - ampliou consideravelmente as concepções iniciais das relações centro-periferia, da deterioração dos termos de intercâmbio, da distribuição da renda e dos desequilíbrios estruturais, construindo uma autêntica teoria do subdesenvolvimento, mostrando que este não podia ser entendido como uma "etapa" no processo de desenvolvimento, mas sim como resultado do processo histórico e da forma específica de como se deu nossa inserção no capitalismo. ${ }^{5}$

Foi precursor da problematização sobre a economia ambiental. Integrou a ecologia à análise econômica e em sua proposta de políticas de desenvolvimento regional, que deram base à formulação, em 1959, de nossa primeira Política de Desenvolvimento para o Nordeste brasileiro. ${ }^{6}$ Mais tarde, em 1972, voltaria ao tema, quando criticou as projeções do Clube de Roma, sobre os limites dos recursosnaturais frente ao crescimento econômico mundial. ${ }^{7}$

4 Os textos clássicos pioneiros da Cepal foram os coordenados e em parte escritos por Prebisch (1949 e 1951), lançando as bases das relações centro-periferia e dos desequilíbrios estruturais dos países periféricos. Os principais desdobramentos podem ser resumidos em termos da questão da Inflação Estrutural (com o clássico trabalho de Noyola); do desenvolvimento de importantes documentos sobre a Importância do Estado e das Técnicas de Planejamento (vários documentos coletivos e alguns de Furtado); sobre a Heterogeneidade Estrutural, (onde desponta o clássico de Pinto); e os pioneiros trabalhos de Furtado, alguns já publicados na primeira metade da década de 1950, e que resultaram na construção de uma Teoria do Subdesenvolvimento Econômico.

5 Ver, sobre esse tema, seus clássicos Desenvolvimento e subdesenvolvimento, Teoria epolítica do desenvolvimento econômico, Formação econômica da América Latina, e Formação econômica do Brasil.

6 Sobre a integração da ecologia, para o caso nordestino, seus textos de 1959 e 1967, e, para o caso dos países subdesenvolvidos como um todo, o de 1974 ( $O$ mito do desenvolvimento econômico).

7 Essa crítica encontra-se em $O$ mito do desenvolvimento econômico. 
São igualmente precursores seus esforços, em várias de suas obras, em integrar a cultura e a importância desta nas discussões sobre o subdesenvolvimento e a questão da Dependência, externa e interna. ${ }^{8}$ Mostra como o desenvolvimento das forças produtivas nos países desenvolvidos possibilitou o crescimento de suas contradições, impulsionando os vários grupos e instituições sociais - trabalhadores, empresários, classe média, Estado, intelectualidade, partidos políticos - a lutarem pela preservação e desenvolvimento de suas culturas. E isto se materializou não só nas conquistas de direitos políticos e sociais, mas também no desenvolvimento da tecnologia, da ciência e das artes. Mas Furtado nos adverte que aqui, no subdesenvolvimento, esse processo não só é truncado, parcial e incompleto, como sofre o controle permanente de suas elites e da forte presença do capital internacional.

Sobre a dependência, especificamente, suas precursoras obras são inequívocas, articulando esse tema, dentro da problemática geral do subdesenvolvimento, ao colocar como elemento central de sua reflexão teórica o problema da má distribuição da renda e da propriedade, herdada da colônia, do escravismo e do primário exportador, e agravado na industrialização. Esclarece, detalhadamente, como isto afetou e afeta o comportamento econômico de nossas elites, impregnadas por uma forte preferência, e até mesmo subserviência, pelos padrões culturais e de consumo externos.

É a partir dessas estruturas distributivas e de consumo que se configuram nossas estruturas de demanda, incompatíveis com nosso nível médio de renda: essa demanda, antes satisfeita por importações, após a Crise de 1929, teria, em grande medida, que ser atendida por produção interna, para a qual, entretanto, não podíamos contar com condições estruturais adequadas - notadamente de tecnologia e escalas de produção. Assim, tornamo-nos reféns de vários oligopólios internacionais que para aqui vieram produzir esses e outros bens mais complexos, ampliando sobremodo nossa dependência externa, entre outras, para com C\&T, patentes, remessas, financiamento externo e balanço de pagamentos. E isto, em última instância, constitui o eixo central e cultural de nossa dependência externa e de nosso subdesenvolvimento econômico, social e cultural.

8 Entre suas principais obras que trataram o tema: Dialética do desenvolvimento, Criatividade e dependência na civilização industrial e Cultura e desenvolvimento. Uma síntese as reflexões de Furtado sobre esse tema está em Burgueño e Rodrigues. 
Embora sempre tivesse como referência as relações internacionais do sistema capitalista de produção, a maior parte de suas reflexões e análises teve por pauta a América Latina e Caribe, e mais profundamente o Brasil. Nesse sentido, seu esforço de síntese teve extraordinário êxito ao produzir dois textos clássicos sobre nossa história, que são Formação econômica do Brasil, de 1959, e Formação econômica da América Latina, de 1969.

Furtado sempre teve rigor no uso da história econômica, distinguindo as diferentes manifestações de determinados processos, como os que ocorreram durante a Colônia, ou na economia nacional, assim como os da escravidão, do primário exportador com trabalho livre, e os decorrentes da industrialização.

Entre as muitas contribuições de Furtado para o melhor entendimento da história econômica da América Latina e do Brasil, destaco algumas das principais, as quais trataram dos seguintes temas:

i) distribuição de renda;

ii) demanda efetiva, crise e crescimento;

iii) estruturas produtivas e de emprego;

iv) uso social do excedente;

v) insuficiência de poupança e investimentos decorrentes do subdesenvolvimento e da distribuição de renda;

vi) tendência ao desequilíbrio externo estrutural;

vii) inflação estrutural;

viii) integração regional latino-americana;

ix) estruturas produtivas primário exportadoras;

$x$ ) questão agrária e agrícola;

xi) questão regional nacional

xii) ecologia e subdsenvolvimento;

xiii) cultura, dependência e subdesenvolvimento.

Sobre a maior parte dessas questões, tratadas ao longo das últimas cinco décadas em sua vasta obra, vários autores se debruçaram, produzindo também uma considerável literatura crítica. Os temas serão tratados de forma resumida, dada a limitação deste texto.

Entre as questões escolhidas, algumas podem ser generalizadas para toda a América Latina, como, por exemplo, a questão fundiária e a das 
estruturas produtivas primário exportadoras, enquanto outras se aplicam mais ao Brasil, como por exemplo a da agricultura itinerante.

\section{Questão fundiária e agrícola}

Embora este tema tenha sido tratado por Furtado em várias de suas obras, limito-me aqui aos problemas apresentados pelo autor em dois de seus livros, especificamente à questão do excedente e das condições de acesso à terra. ${ }^{9}$ Em texto originariamente escrito na década de 1960 , mostra o autor que o emprego agrícola ainda era elevado (em média $40 \%$ da PEA ), e que a agricultura de subsistência (tradicional) tinha a menor produtividade da economia, alta porcentagem de autoconsumo (mais de 50\%), baixo grau de monetização, elevado subemprego e os mais baixos salários. A agricultura comercial (moderna), com mais de $75 \%$ de sua produção indo ao mercado, obtinha produtividade mais alta, mas os salários também eram baixos. Ainda, as condições sociais no campo faziam com que parte dos salários fosse em espécie, tornando ainda mais diminuto o grau de monetização.

Se da produção total agrícola deduzirmos a de subsistência, o resultado, aproximadamente, representaria o excedente do setor, cuja parte in natura era maior do que a monetizada, mas ainda ampliando a sustentação da demanda urbana em expansão. Isso era possível graças aos baixos salários, que condicionam a população rural a um baixo nível de consumo, ampliando assim o excedente. Este é apropriado por vários agentes: proprietários da terra, governo, finanças, transporte etc.

A expansão e diversificação da estrutura produtiva dessa economia dependem, assim, de duas coisas: o volume do excedente e a forma de sua utilização. Esta, se voltada mais para a satisfação de consumo conspícuo ou outros gastos improdutivos, geralmente importados, não possibilitará o aumento do investimento e, portanto, da capacidade produtiva da economia e de sua diversificação.

A questão do acesso à terra é sinteticamente mostrada por meio da construção de uma matriz com duas colunas, referentes ao acesso à terra, se difícil (a) ou se fácil (b) e duas linhas, referentes à sua disponibilidade, se abundantes (c) ou escassas (d). Além disso, Furtado tece várias considerações sobre qualidade da terra, problemas ecológicos, condição de ocupação da terra etc. Na situação $\mathrm{AC}$, podem existir problemas sérios de

9 Sobre o tema ver Furtado (1969, cap. vii; 1972, cap. ii; 2000 cap. 15; e parcialmente, em 1961, cap. 4.) 
ecologia, infraestrutura, desmatamento e ocupação que provoca rápida exaustão da fertilidade natural, predominando uma agricultura familiar tradicional, de baixa produtividade, convivendo ao lado de uma capitalista, para a qual é reservada mão de obra barata.

Na BC, de rara ocorrência, predomina a agricultura familiar tradicional ou moderna, com possibilidades de melhor nível de vida para ambas. Na AD, a situação é a pior, predominando uma agricultura tradicional não capitalista, em situação de precária posse e ocupação, convivendo com o latifúndio tradicional.

$\mathrm{Na} \mathrm{BD}$, a introjeção de progresso técnico é indispensável para que a agricultura familiar possa aumentar sua eficiência e sobreviver, pois, em geral, nessa situação está presente o velho problema da divisão da pequena propriedade, e a proliferação do minifúndio, podendo haver reversão para uma agricultura de subsistência.

Da dinâmica dessas estruturas e do crescimento da população rural depende o grau de evolução desse setor, a geração de excedente e a melhoria ou piora das condições de vida de sua população. O exame de casos específicos, por meio dessa tipologia, permite o avanço para as reflexões sobre políticas de reforma agrária, distribuição da renda, emprego, concentração de poder econômico e político etc.

\section{Inserção externa e estruturas produtivas primário exportadoras}

A segunda questão que escolhi é a referente ao tratamento que Furtado deu à inserção externa latino-americana no início do século XIX, e as estruturas produtivas internas decorrentes dessa inserção primário exportadora. Já em 1959 (e mesmo um pouco antes, em outros textos), sua Formação econômica do Brasil tratou desse tema, no que se refere a nosso país, a partir do século XVI . Em 1969 publica outro texto clássico - Formação econômica da América Latina, reeditado em 1975 como Economia latino-americana -, onde, nos capítulos 4 a 6, trata o tema em âmbito regional.

Embora não apresente sua discussão em forma matricial, uso esse instrumento (não em termos matemáticos), tentando colocar nessa forma os temas e problemas postos por Furtado. As três linhas dessa matriz apresentam as principais atividades resultantes daquela inserção: a mineração do século XIX, a agricultura temperada e a agricultura tropical. As linhas também contemplam a informação de em que países essas 
atividades ocorreram ou eram as proeminentes.

Nas colunas coloquei: i) o uso de terra, sua extensão e intensidade; ii) a forma do uso ou de propriedade dessa terra; iii) o emprego de trabalhadores; iv) o grau de intensidade de ciência e tecnologia que cada atividade utilizava; $v$ ) a capitalização, ou seja, a intensidade ou não de capital em cada uma delas; $v i$ ) a presença ou não do capital internacional como proprietário de terras; e vii) o tipo de fiscalidade que o Estado poderia obter em cada atividade e o âmbito maior ou menor em que poderia mover a política pública.

Dessas intersecções se deduzem as estruturas possíveis de mercado de trabalho, de distribuição de renda, nível de produtividade, de inserção no mercado externo, vias possíveis da fiscalidade, e as estruturas de poder, ou seja, o espaço de ação do Estado vis-à-vis o poder do capital internacional e das oligarquias rurais. Do movimento da economia e da manutenção dessas estruturas decorrem, em grande medida, as principais determinações ou possibilidades sobre o emprego, salários, sindicalização, estruturas de poder político, fiscalidade de governo, grau de progresso técnico, a concentração da propriedade da terra, do dinheiro e da renda.

\section{A agricultura itinerante}

O terceiro tema é mais específico ao Brasil, mas pode se manifestar também em outros países, notadamente nos de maior espaço territorial. Em suma, trata-se do fato de que, à medida que a agricultura moderna, basicamente a de exportação, se expande, aumenta sua necessidade de terra, resultando na expulsão, para o interior, de outras atividades rurais, seja a pecuária, o latifúndio Improdutivo ou a agricultura tradicional, de pequena propriedade, parceria, ou de simples ocupação.

Ele trata esse fenômeno na Formação econômica do Brasil, principalmente nos capítulos 8 a 12 onde explica a formação do complexo nordestino, mas faz uma reflexão e teorização mais profunda no seu livro Análise do modelo brasileiro no capítulo II. Esta é uma de suas principais contribuições para o entendimento de nosso país. É, sem dúvida, uma contribuição que reputo brilhante.

Na Formação econômica do Brasil, Furtado examina o movimento da expansão açucareira entre os séculos XVI e XIX e, embora tenham se passado trezentos e tantos anos de ocupação e atividade, ele se dá conta da profunda e conservadora estabilidade econômica e social do Nordeste, com a 
manutenção do atraso, da baixa eficiência, da elevada concentração da propriedade e da renda, e a manutenção das estruturas tradicionais de poder.

Em Análise do modelo brasileiro, explica em maiores detalhes como é que se dá o fenômeno da agricultura itinerante, ou seja, de à medida que a estrutura da cana-de-açúcar se expandia, ela empurrava para o interior a pecuária e a agricultura do pequeno produtor, em geral do tipo familiar, resultando a esta, terras de qualidade inferior e mais distante dos mercados. Mostra, assim, a contínua marginalização do pequeno e médio produtor, e a impossibilidade dessa pequena produção competir com aquela estrutura escravista e latifundiária, e não raro transformar-se em mero reservatório de mão de obra, seja como trabalho barato na própria agricultura moderna, seja como morador de condição no latifúndio improdutivo ou na pecuária tradicional. O processo aumenta incessantemente o desmatamento, intensificando aquela interiorização, e gerando estruturalmente uma imensa fábrica de miséria social.

Na segunda obra mostra que o fenômeno não se deu exclusivamente no Nordeste, tendo ocorrido também na cafeicultura do Vale do Paraíba. Ali, o café produziu o mesmo movimento, ou seja, à medida que essa atividade se expandia, ia tomando novas terras e empurrando as antigas roças do pequeno produtor, do posseiro agrícola; empurrou esta gente para o interior e, portanto, a marginalizou.

Suas primeiras reflexões estão datadas. A primeira, em 1959; a segunda em 1972, quando nossa agricultura iniciava sua grande modernização conservadora, principalmente via intensificação do uso de equipamentos e de uso de produtos químicos. Certamente, em 1972 ainda não dispunha das informações sobre as transformações técnicas ocorridas após a primeira metade da década de 1960.

Por isso, Furtado se atém ao período anterior a 1965, denunciando que, no açúcar e no café escravistas, o trabalho barato e as terras baratas compensavam amplamente a baixa eficiência e a pouca tecnologia empregada. Em trabalho recente, tentei atualizar para as últimas décadas essas ideias tratadas por Furtado, constatando que o fenômeno da agricultura itinerante continua a se manifestar em todos os espaços nacionais penetrados pela agricultura moderna, notadamente a de exportação. ${ }^{10}$ A diferença fundamental, em relação às constatações de Furtado, é que agora (após a segunda metade da década de 1960) é grande a introjeção

10 Esse texto é o capítulo 5 de meu livro Ensaios, no qual também mostro como outros autores trataram essa questão sobre o Brasil. 
de progresso técnico. O trabalho escravo foi substituído pelo livre e continua a ser barato, e a terra continua a ter oferta elástica e preços também baratos, e a infraestrutura (e vários subsídios) concedida pelo Estado continua a rebaixar os custos de produção. A outra novidade é que à expansão das culturas e pecuária de exportação, juntou-se a atividade extrativa de madeira, também de exportação, mas seus efeitos são tão ou mais cruéis do que antes: o desmatamento aumentou consideravelmente e a miséria social se ampliou nesses novos espaços da Amazônia, do Centro-Oeste e do próprio Nordeste.

\section{A questão regional}

Embora Furtado tenha estudado os diferentes espaços regionais do Brasil, sua principal contribuição neste tema se refere à formação do complexo nordestino, tema de forte presença na Formação econômica do Brasil, mas que seria tratado de forma mais profunda, detalhada e mais sistematizada em outros dois textos, haja vista que seu diagnóstico se destinava a embasar a formulação da proposta de uma política econômica para o desenvolvimento do Nordeste, em 1959, ao final do governo JK.

A matéria está tratada basicamente em dois textos antigos: um está assinado (A Operação Nordeste) e o outro não - este é o famoso documento do Grupo de Trabalho para o Desenvolvimento do Nordeste (documento que passaria a ser conhecido por GTDN ), cuja autoria só foi confessada por ele recentemente, e até então se imaginava que o texto fosse produto de um grupo colegiado."

Em que consiste o diagnóstico que ele fez? É um diagnóstico fantástico, que mostra inclusive as contradições ecológicas do semiárido nordestino, vis-à-vis o tipo de uso que se dava para aquele solo. Seu diagnóstico e proposta mostram que a solução para esse espaço não se circunscrevia à questão da água, e sim à de transformar a ocupação e a economia da região: diminuir fortemente a área da agricultura produtora de alimentos - que não conseguia resistir às secas mais fortes - ; reconcentrar a propriedade, ou seja, uma reforma agrária às avessas no semiárido, para que justamente a maior dimensão nos estabelecimentos pudesse dar guarida a uma atividade agrícola de exportação ou criação de gado com mais eficiência do que antes.

11 A questão da autoria está esclarecida em seu livro A fantasia desfeita. Em meutexto citado na nota anterior reproduzo e comento as ideias centrais contidas no importante documento GTDN . 
A proposta contemplava a retirada, daquele espaço, de cerca de um milhão de pessoas, que seriam reassentadas: parte, com a implantação de um grande programa de colonização no sul do Maranhão; parte, em outros projetos com irrigação, nas chamadas manchas e vales úmidos; $\mathrm{e}$ outra parte nas áreas propostas para reforma agrária na Zona da Mata. Esta última, aliás, era imaginada como de menor problema político, haja vista que as terras seriam as que se tornariam dispensáveis pela cultura da cana-de-açúcar, em função do programa de sua modernização, também proposto por Furtado, e financiada pelo Estado.

Esse assentamento da Zona da Mata tinha o intuito de não só dar sustentação social para aquela gente sofrida como também o de dar àquela terra uso mais produtivo, para aumentar a oferta de alimentos e com isso dar apoio logístico à industrialização programada, o componente mais dinâmico daquela política.

Por outro lado, o programa combatia a velha e surrada "solução hidráulica”, que consistia basicamente na política de armazenamento de água, ferrenhamente defendida pelas elites nordestinas, e que, no fundo, consistia em um poderoso instrumento de dominação. Furtado sempre lutou contra a "solução hidráulica" e propôs uma solução ecológica e social que deveria se concretizar após a implantação da Sudene, uma instituição que muito honrou este país e que nos seus primeiros anos teve um corpo técnico de alto nível, que realmente lutou pelas condições do Nordeste. Lamentavelmente, o golpe de 1964 derrotou a proposta de Furtado, e a onda de neoliberalismo que estamos vivendo encarregou-se de liquidar com mais essa instituição pública em 2001, recriando-a em 2007, mas com poder e orçamento reduzidos. Embora a ideia da transposição de água do Rio São Francisco seja muito antiga, ela nunca foi proposta por Furtado, nem por quem lhe sucedeu na Sudene.

\section{A mineração do ouro em Minas Gerais (Século XVIII)}

O quinto ponto que selecionei está contido nos capítulos de 13 a 15 da Formação econômica do Brasil, em que Furtado examina a formação, auge e exaustão da economia da mineração do ouro em Minas Gerais no século XVIII. Furtado analisa essa economia utilizando uma metodologia de corte estrutural e em parte keynesiana, e a compara com a outra economia colonial e também escravista daquele momento, a açucareira nordestina.

Desse confronto consegue dissecar as duas estruturas, mostrando suas 
principais diferenças, notadamente quanto ao grau de capitalização, emprego humano, produtividade e rentabilidade, agregando ainda importantes considerações de ordem social. Ao analisá-la, realça e aprofunda três questões importantes. ${ }^{12}$

O ensaio precoce de integração no mercado nacional gerado pela economia da mineração, dadas as articulações inter-regionais que aquela atividade engendrou para o Nordeste, pela demanda de gado bovino; para a pecuária do Sul, com o gado muar e bovino; com o comércio de gado e a produção de alimentos em São Paulo; com o comércio e a administração pública do Rio de Janeiro; e com a criação dos primeiros caminhos de infraestrutura, ligando a região mineradora ao Nordeste, ao Rio de Janeiro, a São Paulo e ao extremo Sul.

Embora não desenvolva o tema, nos dá as pistas necessárias (notadamente nocapítulo 20, de Formação econômica do Brasil) para que possamos entender como, vinda a terrível depressão causada pela exaustão da mineração, o capital (na forma de ativos físicos), deixa de valorizar-se e retorna à forma de riqueza, para, no futuro, sofrer nova metamorfose, voltando à forma de capital.

Este fenômeno ocorreu na gestação da economia cafeeira, que pode usar antigos ativos remanescentes da mineração, como escravos, ouro entesourado ou contrabandeado, tropas muares, fazendas produtoras de alimentos, e a infraestrutura, que hibernaram durante o final do século e o início do século XIX, mas que vão renascer na forma de capital para a cafeicultura. ${ }^{13}$

A terceira é sua conclusão sobre a impossibilidade de ocorrer a industrialização após a crise da mineração. Para tanto, enfatiza a exaustão das minas e, com isso, a inexorável regressão do mercado da região, além do despreparo técnico da mão de obra trazida por Portugal. Sua análise causou conhecida polêmica com outro autor, levando-me a confrontar as duas análises, em ensaio que fiz sobre essa economia, repondo o acerto de Furtado. ${ }^{14}$

12 Obviamente, o texto de Furtado não se limita às três questões acima destacadas.

13 Sobre essa metamorfose riqueza-capital, ver Cano (2002, cap. 1)

14 A crítica foi feita por Castro (vol. 2, 1971), que tenta explicar a não industrialização por causa do Edito de 1785, hipótese descartada por Furtado, e negar os argumentos deste. Em meu texto Ensaios (cap. 1) reproduzo a controvérsia e a critico, repondo as razões apresentadas por Furtado e acrescentando outras questões que julgo pertinentes. 


\section{Crise de 1929, a defesa da economia nacional e a industrialização}

O sexto ponto constitui um modelo de análise macroeconômica keynesiana que é o estudo que Furtado fez sobre a Crise de 1929 no Brasil (capítulos 28 a 32 de Formação econômica do Brasil) e que posteriormente estenderia à América Latina em Formação econômica da América Latina.

Sua análise - que não contém nenhum erro teórico ou empírico, e é uma peça clássica na historiografia econômica brasileira - sofreu um ataque irresponsável por parte de um crítico impregnado de forte viés ideológico de direita que veio ao Brasil durante o regime militar, aparentemente com o esdrúxulo objetivo de tentar destruir política e ideologicamente a obra de Furtado. ${ }^{15}$ Fiz-lhe a crítica, restaurando a justeza da análise de Furtado, e mostrando alguns erros grosseiros cometidos pelo pretenso crítico. ${ }^{16} \mathrm{~A}$ análise de Furtado é muito conhecida, razão pela qual não é necessário reproduzi-la. Seu crítico — Peláez — tenta mostrar que Furtado é um equivocado, e que suas afirmações sobre a intervenção do Estado durante a crise, e os efeitos derivados dessa política econômica, foram muito reduzidos, e que, na verdade teria sido o saldo da balança comercial o responsável pela recuperação da economia brasileira.

Tenta negar que foram o financiamento e o gasto público os principais responsáveis pela retomada da demanda efetiva, ao mesmo tempo que afirma que esses gastos teriam sido feitos para outros fins (as secas do Nordeste em 1931-1932 e a Revolução Paulista em 1932). Afirma que a política monetária do governo revolucionário era ortodoxa, porque ortodoxos eram os seus ministros e para provar, mostra a evolução nominal dos meios de pagamento, que caem. Diz, ainda, que Furtado afirmou que houve transferências de lucros da cafeicultura para a indústria, afirmação essa que na verdade inexiste.

Minha crítica a esse texto de Peláez foi precedida pela de Silber, que apontou alguns erros grosseiros, entre os quais o de Peláez analisar apenas a política feita para atender à safra de 1931-1932, quando a política de sustentação cafeeira foi até 1943, e os equívocos sobre a suposta ortodoxia da política monetária. Assim, detendo-se apenas naquele curto período, tentou ocultar as ações públicas desenroladas mais à frente, estudadas por Furtado. ${ }^{17}$

15 A crítica a Furtado está em Peláez (1968).

16 Minhas críticas estão em Cano (2002, cap. 4).

17 Esse texto é o de Silber (1977), que levanta os grosseiros "erros" de Peláez, 
Minhas críticas aqui abarcarão os seguintes pontos: os efeitos dos saldos comerciais, a suposição de ortodoxia da política monetária e orçamentária, a suposta transferência de lucros da cafeicultura para a indústria e a questão da industrialização. Para a questão dos saldos comerciais bastaria ler a obra de Kalecki, que nos ensina que em termos de dinâmica da demanda efetiva, não basta examinar os saldos, positivos ou negativos, mas sim examinar concretamente se tais saldos são frutos de uma expansão mais que proporcional das exportações que poderiam, com isso, ativar setores produtivos internos e não apenas gerar um saldo. Nós tivemos muitos saldos a partir de 1930, mas são saldos de depressão, resultados de quedas concomitantes de exportações e importações, e que, portanto, não seriam responsáveis por efeitos de recuperação da demanda efetiva.

Com relação à suposta ortodoxia, "percebida" na leitura de discursos de nossos ministros da Fazenda, lembraria que a análise de discurso é um instrumento complexo e que precisamos tomar cuidado para fazê-la. Aquele crítico parece não ter se dado conta de um fenômeno econômico pouco trivial quando nos defrontamos com uma depressão tão profunda como foi a de 1929. É que houve deflação. Portanto, ele teria de pegar a série de expansão de meios de pagamentos em termos nominais e usar índices de preços para ver se houve contração monetária ou não. E quando usamos os deflatores do período, resulta uma série em termos reais, crescente, mostrando uma política expansionista e nada ortodoxa.

No que tange à questão orçamentária, já em parte criticada por Silber, o exame da realidade mostra que, mesmo se retirarmos os gastos com as secas e com a Revolução, os déficits públicos que ocorrem nos anos posteriores a 1930 são consideravelmente maiores que os déficits de 1928, o que mostra uma política também expansionista e não ortodoxa.

A questão da transferência de lucros para a indústria nunca foi escrita por Furtado em nenhuma versão ou tradução da Formação econômica do Brasil. A propósito, com a dimensão da depressão sofrida pela cafeicultura, é difícil imaginar como esses lucros poderiam existir, em quantidade apreciável. O que Pelaéz não conseguiu entender é que, numa crise brutal como a do café, alguns importantes recursos empregados pela cafeicultura poderiam, sim, ter sua transferência física para outras culturas da agricultura ou da pecuária, como terras, trabalhadores, máquinas,

principalmente os de tratar exclusivamente da safra 1931-1932 e à suposta ortodoxia fiscal e monetária do governo. 
meios de transporte e de armazenagem. É o que de fato ocorreu, principalmente com a cotonicultura de São Paulo, cujo produto não sofreu queda de preços tão intensa como os do café, haja vista a proteção que o governo dos EUA deu a essa cultura naquele país.

Por último, vejamos algo sobre a industrialização. Primeiro, Furtado foi extremamente cuidadoso, ao lembrar que havia grande capacidade industrial ociosa, com o que, o investimento líquido, em curto prazo, não seria crucial. O necessário, e foi isso que Vargas fez, foi ativar os gastos típicos de uma política anticíclica, com o amparo dado à cafeicultura. Mas, deve-se registrar para evitar equívoco, isto não quer dizer que a industrialização que passa a se manifestar e, logo em seguida, dirigir o novo padrão de acumulação, fosse "espontânea". ${ }^{18}$ Ao contrário, a visão progressista do governo evolucionário não demorou a enveredar por uma política deliberada de industrialização. Não instantânea e imediatamente deliberada, é claro.

Se não tivéssemos uma capacidade ociosa industrial como tínhamos durante a depressão, as políticas anticíclicas poderiam apenas restaurar o consumo. Mas isto seria uma quimera, pois não teríamos nem divisas para importar os bens de consumo, nem teríamos capacidade produtiva para produzi-los. Nossa capacidade ociosa, é preciso lembrar, não era apenas de bens de consumo, pois tínhamos acabado de montar dois compartimentos que iam ser extremamente importantes nesses primeiros anos da crise, que eram a primeira fábrica nacional de cimento e a primeira siderurgia não integrada, que cumpririam importante papel nesse período.

É bom também lembrar que nenhum dos velhos cepalinos, muito menos Furtado, falou em industrialização espontânea e tampouco no absurdo de uma suposta "teoria dos choques adversos", como responsável por nossa industrialização.

\section{Dependência, exacerbação financeira e crise: grandes obstáculos para governar, crescer e distribuir}

Em dezembro de 2001 e em novembro de 2004 (cerca de um mês antes de falecer) foram publicadas duas importantes entrevistas concedidas por Furtado à revista Carta Capital, ${ }^{19}$ analisando aqueles respectivos

18 Ver, a esse respeito, os comentários críticos que Prebisch fez no Prólogo do livro de Rodriguez (1986, p. viii).

19 Edições de 26/12/2001 (p. 72-77) e de 1/12/2004 (p.46-5o). 
momentos e fazendo alguns prognósticos sobre a situação política e econômica do país. Em ambas retoma suas reflexões sobre a desigualdade reinante no país, a fragilidade da cultura nacional e os reflexos que isso e mais a exacerbação financeira exerciam sobre as estruturas de poder, além dos constrangimentos que causam sobre o desenvolvimento da economia.

Na primeira, recolocou suas reflexões sobre a especificidade do subdesenvolvimento, em contraposição com o que dizia o governo de FHC, de que "éramos um país injusto, e não um país subdesenvolvido", no sentido de que a palavra justiça era absolutamente insuficiente para explicar as razões e os processos cumulativos daquela desigualdade e da dependência. Fez, então, severas críticas às nossas elites - cosmopolitas, como pensam ser - , mostrando que seus desejos de reproduzir os elevados padrões de consumo dos países desenvolvidos implicavam, necessariamente, em exclusão social e aumento da dependência externa e interna. E afirmava: "ela sabe o que quer, ela quer ir para Miami viver como se vive lá". Lembrou ainda que a globalização estava reproduzindo esse fenômeno no mundo inteiro, como já mostravam as estatísticas mundiais sobre a forte concentração da renda pessoal a partir da década de 1980. Já nessa entrevista, lamentou a alienação de grande parte dos economistas nacionais, que aceitaram acriticamente esses fatos e essas (e outras) "novas teorias". Muitos deles, inclusive vários que se consideram heterodoxos, aceitaram tranquilamente a substituição da palavra subdesenvolvido pelos novos epítetos batizados pelo BIRD , como emergentes, ou ainda, países em desenvolvimento, negando, com isso, os ensinamentos de Furtado e a própria teoria do subdesenvolvimento econômico.

Enfatizou a necessidade de alterar profundamente a política econômica, reduzindo os juros e controlando o câmbio e os fluxos de capital, mas, para isso, seria preciso ter coragem política, como a que tiveram alguns homens públicos (notadamente Vargas) entre 1930 e 1960. Concluía que a "única explicação que tenho para que o Brasil não tome uma atitude mais firme em matéria de reajustamento internacional dos fluxos financeiros é medo, é medo de que os capitais fujam do Brasil". Não é demais lembrar que naqueles oito anos de mandato (1995-2002), o déficit em transações correntes acumularia US\$ 200 bilhões, nossa dívida externa dobrou (US\$ 228 bilhões) e nossa Posição Internacional de Investimento ${ }^{20}$

20 É o novo termo técnico usado pelo BCB, em substituição ao antigo, o Passivo Externo Liquido. 
já era de US\$ 227 bilhões. Estávamos, então, no final de um mandato presidencial e próximos das eleições de 2002.

Furtado depositou grande esperança de que nesse ano ressurgiria com força o debate nacional sobre os novos rumos que a política econômica deveria tomar, diante de uma possível vitória da oposição. Como se sabe, amargaria mais três anos de dissabor, amenizados, em parte, por algumas decisões de políticas sociais implantadas pelo novo governo, pelos ventos de crescimento que emanavam do Oriente, e que nos deram um alento no crescimento a partir de 2003. ${ }^{21}$

No momento da segunda entrevista, Furtado sabia que as contas externas haviam tido pequena melhora, com saldos positivos em transações correntes, pequena diminuição da dívida externa e acentuada diminuição de ingresso líquido de capitais estrangeiros, em grande parte decorrente da crise cambial de 1999-2002.

Contudo, as pressões fiscais causadas pela dimensão das taxas de juros, de seu enorme peso nas contas públicas e a pressão resultante no câmbio, valorizando-o, exigia uma firme atitude do governo, talvez, como sugeriu, uma moratória (negociada) programada e uma indispensável reforma fiscal de caráter progressista. Previa que, ao longo da década de 2010, essa situação se tornaria insustentável, limitando ainda mais, e severamente, a já baixa autonomia do governo no exercício da política econômica, e da própria política.

Também previa, no cenário internacional, a eclosão de uma grave crise internacional, a menos que se fizesse profunda reestruturação do sistema financeiro internacional. "A crise já se instalou, ainda que não seja reconhecida", disse. ${ }^{22}$ E concluía que, se assim continuasse, o país teria de se endividar permanentemente, desfazendo-se do restante de seu patrimônio público e abdicando do pouco de soberania que ainda lhe restava no manejo da política econômica. Suas corretas sugestões, contudo, não tiveram eco no cenário político nacional, inclusive no governo.

O que diria Furtado hoje, se constatasse que:

i) a dívida externa bruta mais que dobrou, atingindo US $\$ 556$ bilhões em dezembro de 2014, quando nosso passivo externo líquido atingiu US\$

\footnotetext{
21 Lembremos que no primeiro mandato (2003-2007) de Lula, a política econômica praticamente não teve alterações, e os poucos sinais progressistas se restringiam ao anúncio do crédito consignado ao trabalhador, em 12/2003, e ao pequeno aumento do crédito ao setor privado a partir de 2004, o qual aumentaria fortemente a partir de 2007

22 Carta Capital de 1/12/2004, p. 47.
} 
786 bilhões;

ii) o saldo em transações correntes acumulou US\$ 100 bilhões na crise 2008- 2010 e US\$ 298 bilhões entre 2011 e dezembro de 2014;

iii) as maiores causas desse enorme rombo entre 2011 e dezembro de 2014 foram: a) a enorme sangria da remessa de rendas (-163 bilhões) gerada pela

desregulamentação e descontrole do câmbio e do capital; b) as enormes importações de bens de consumo (- US\$ 103 bilhões); e c) os irresponsáveis gastos em turismo (- US $\$ 75$ bilhões).

Provavelmente, ficaria surpreso pela rapidez dessa deterioração, e talvez dissesse que sua hipótese negativa sobre a possibilidade de um governo de oposição, nessas condições, exercer seu mandato com certa autonomia, estaria ainda mais fortalecida.

Ainda mais desapontado ficaria ao saber que, dias depois da dura e estreita vitória eleitoral de $26 / 10 / 2014$, a presidente anunciaria alguns nomes de seu novo ministério, escolhidos entre as preferências do setor financeiro e das oligarquias conservadoras. 